\title{
The diagnostic role of hyperferritinemia in a tertiary care pediatric rheumatology setting
}

\author{
I Sala*, L Trail, B Lattanzi, N Solari, E Palmisani, A Parodi, C Malattia, \\ A Buoncompagni, A Loy, A Martini and A Ravelli
}

Address: IRCSS G. Gaslini, Genova, Italy

* Corresponding author

\author{
from $15^{\text {th }}$ Paediatric Rheumatology European Society (PreS) Congress \\ London, UK. 14-17 September 2008 \\ Published: 15 September 2008 \\ Pediatric Rheumatology 2008, 6(SuppI I):PI92 doi:10.I 186/I546-0096-6-SI-PI 92
}

This abstract is available from: http://www.ped-rheum.com/content/6/SI/PI92

(c) 2008 Sala et al; licensee BioMed Central Ltd.

\section{Background}

Serum ferritin is a laboratory marker that reflects the level of macrophage activation in systemic inflammatory illnesses. Sharply increased levels of ferritin are usually found in the acute phase of macrophage activation syndrome (MAS).

\section{Objectives}

1) To investigate the prevalence of hyperferritinemia (ferritin $>500 \mu \mathrm{g} / \mathrm{dl}$ ) in patients with systemic inflammatory conditions who had this laboratory test requested in the context of the diagnostic workup. 2) To determine the prevalence of specific diagnoses among patients with hyperferritinemia.

\section{Results}

More than 4000 determinations of ferritin requested by the study unit were performed between January 2004 and December 2007 by the central laboratory of the study hospital. Hyperferritinemia was found in 408 determinations in 87 patients. The most common specific diagnoses in patients with hyperferritinemia were the following: systemic juvenile idiopathic arthritis (sJIA) (48.3\%), systemic lupus erythematosus (SLE) (5.7\%), protein intolerance with lysinuria $(4.6 \%)$, virus-associated haemophagocytic syndrome (3.4\%), hematologic disorders $(3.4 \%)$, juvenile dermatomyositis $(2.3 \%)$, polyarticular JIA $(2.3 \%)$, systemic vasculitis $(2.3 \%)$, autoinflammatory syndrome $(2.3 \%)$. Twelve patients $(13.8 \%)$ had a nonspecific systemic inflammatory syndrome. Twenty-seven
(31\%) of the 87 patients with hyperferritinemia developed features consistent with MAS.

\section{Conclusion}

The most frequent specific diagnoses in patients with hyperferritinemia were sJIA and SLE. However, hyperferritinemia was seen in a number of children with systemic inflammatory syndromes, which were mainly characterized clinically by persistent fever, but did not fit any specific diagnostic categories and remained of undetermined etiology. Around one third of the patients with hyperferritinemia developed features consistent with MAS. 